\title{
CULTURE AND INSTITUTIONS IN THE ECONOMIC DEVELOPMENT OF KOREA \\ by
}

Chung H. Lee*

Working Paper No. 89-9

August 2, 1989

* Professor of Economics, University of Hawaii at Manoa and Research Associate at East-West Resource Systems Institute, Honolulu, Hawaii. 


\section{Introduction}

The question of how culture and institutions may affect the economic development of a country has a long history going back to the publication of Max Weber's The Protestant Ethic and the Spirit of Capitalism (1920). More recently, the same question was raised by Hoselitz (1952, 1960), Hagen (1962), Myrdal (1968), and Bauer (1972), but their answers and ideas have neither been incorporated into mainstream economics or economic development thought nor led to further refinement and empirical tests. ${ }^{1}$ As a consequence, understanding cultural and institutional influences on economic development still remains perhaps the most challenging task in social science. ${ }^{2}$

In recent years, the emergence of Japan as an economic superpower and the rapid industrialization of Hong Kong, Korea, Singapore, and Taiwan have again brought attention to the role of culture and institutions in economic development. Certainly, government policies do matter in bringing about an efficient allocation of resources and their effective utilization. But, if achieving economic development is just a matter of adopting good government policies, one must wonder why there are still so many countries in the world that cannot even provide the basic needs to their people. It is thus natural to search for additional factors besides good government policies to explain the successful cases. As these successful Asian economies all share the Chinese culture and values, it is natural to ask whether their common cultural background has been a crucial factor in their economic success.

If culture and institutions based on it are key elements in the economic success of these economies, then the adoption of the policies that have worked so well for them may not work as well for other developing countries. Which role culture has played and how important it is in their economic development 
are, therefore, questions of great interest for policy makers as well as academic researchers. ${ }^{3}$

Cultural influence permeates every aspect of human behavior and conduct. For analytical purposes, however, it may be divided into two groups. The first consists of the effects of culture on the behavior of an individual himself. Examples of these are attitudes toward education and work ethic and preferences over work and leisure and over present and future consumption. The second group consists of the effects of culture on transactions between various decision-units in the society. The effects of culture on the relationship between workers and managers within a firm, the relationship between firms, and the relationship between government and business belong to this second group.

Any transaction between different decision-units in the society requires an explicit or implicit contract involving the exchange of a commodity or property right and its fulfillment by the contracting parties. By establishing the norms for such relationships culture affects the way contracts are arranged and fulfilled and thus the way transactions are carried out.

The cost of a transaction relates to the difficulty in fully specifying a contract for all possible contingencies and thus to the possibility of opportunistic behavior by efther party of the contract. Arrangements will be made to curb this possibility, and the arrangements or institutions that minimize transaction costs will be eventually adopted for a given type of transactions (Williamson 1986). Since culture influences the way interpersonal transactions are carried out and since it has different effects on alternative institutions for a given type of transactions, a transactioncost-minimizing institutions that the society will adopt depends on its 
culture.

Besides affecting the type of institutions that the society adopts for a given type of transactions, one culture may be more conducive to economic growth than others. Transaction costs are the "cost of running the economic system" (Arrow 1969, p. 48); and it is clear that an "ideal" society where everyone is honest and law-abiding and where transactions are routinized as there is little change in culture and technology will run smoothly with a minimum of transaction costs. Such a society can devote more of its resources to productive activities and thus will be able to produce more from given resource endowment. The question, therefore, is what are the cultural characteristics that would reduce transaction costs and which culture has these characteristics.

As noted above, there are various relationships in a society on which culture has influence. This paper will, however, focus on one particular case: the effect of the Confucian culture on the relationship between government and business in Korea. Although the role of government in economic development is still very much debated, it is not difficult to see that which role it plays and how it carries out the role would depend on the cultural norms underlying the relationship between government and business.

Section II briefly reviews the literature on the role of government in economic development and section III then describes government-business relations in Korea. Section IV addresses the cultural foundation of these relations and section $V$ points out that the Confucian orientation has helped the government implement its policies efficiently and in a way different from the ways of the West and America. The final section concludes with some speculation on how the relations between government and business will evolve as the economy becomes more complex and developed and as the political system 
becomes more democratic.

II. The Role of Government in Economic Development

It is now widely accepted that the cause of the success of the Asian economies in achieving high rates of export and economic growth is their adoption of an outward-oriented development strategy in the early 1960s. The strategy consists of policies which provide equal incentives to both exports and import-substitutes and minimize uncertainty over the structure of incentives (Balassa 1980 and 1981). Thus, adopting such a strategy means essentially removing or compensating for man-made obstacles to efficient resource allocation and international trade, and attributing rapid export and economic growth to such distortion-correcting policies implies, therefore, a highly elastic response of the private sector to price incentives. The strategy also implies the role of government which is limited to setting correct relative prices and is severely restrained in the exercise of command and discretionary measures.

This is not, however, a view shared by all (e.g., Johnson 1985, Kim 1988, Lee and Naya 1988, Mardon 1989, Whang 1987). In his comparative study of Taiwan and Korea, Scitovsky (1985) observed that while relying on market forces to take their course the Taiwanese government had employed various measures of control to implement its growth policies as set out in a succession of Four-Year Plans. In the case of Korea there was, he noted, a much more forceful and aggressive political leadership in the pursuit of economic growth. Thus, Scitovsky's characterization of the role of government in Korea is not quite consistent with that implied in the outward-oriented development strategy. The Korean government played more than a passive function, intervening directly with markets with commands and discretionary 
measures. As a matter of fact, one can even find the term "state capitalism" in the initial government development plan of the Park Chung Hee regime. Perhaps more appropriately, as described by Jones and Sakong (1980), the role of the Korean government was that of a senior partner in a partnership with business.

If economists are generally amiss in neglecting or dismissing as inconsequential direct government intervention in the Korean economy and its effect on export and economic growth, those who see dirigisme as a cause of Korea's economic success lack, however, any plausible explanation of why it has contributed to the success. They tend to take the observed association between direct government intervention and the economic success as a selfevident causal relationship and are unable to respond to the argument that the economy has done well in spite of government intervention.

Arguments in favor of direct government intervention has been made in terms of externalities, economies of scale, and learning-curve economies (Wade 1985). It should be pointed out, however, that functional incentives such as taxes and subsidies can be used to correct for externalities and learningcurve economies and economies of scale can be realized in an outward-oriented economy without the distorionary effects of monopoly. In other words, externalities, economies of scale and learning-curve economies may constitute a basis for government intervention with markets but not for the type of intervention observed in Korea.

Johnson (1985) describes the type of intervention observed in Korea as a "market-conforming" method of intervention. Lim (1981) goes one.step further, calling it "market sustaining" intervention. Market-conforming or marketsustaining methods of intervention are effective in promoting growth and exports, according to Johnson, as in such an economy a public system is 
committed to developmental goals whereas a private system pursues profit motives. How the interaction between the two systems works to achieve societal goals of economic development is explained in the following quote (Johnson, p. 68).

The interaction between the two affects the nature of the decisions made in both systems. The intent of the public system is to manipulate the inputs into the decision-making processes of privately owned and managed enterprises in order to achieve development goals, but the content of its inputs is continuously affected by feedback on profit-and-loss conditions, export prospects, raw materials costs, and tax receipts. The intent of the private system is to maximize profits, limit risks, and achieve stable growth given the political-economical environment in which it must operate, but its decisions on products, markets, and investments are continuously affected by changing costs and availability of capital, export incentives, licensing requirements, and all the other things the government manipulates.

It should be pointed out, however, that what is unique about the Korean case described above is the way the interaction is carried out and not the interaction itself. Even the United States has such two systems. Its public system may not be as development-oriented as its counterpart in Korea but the private one is certainly as profit-maximizing as that in Korea. The key difference has to be that in the United States the interaction is carried out mostly through price signals and at arm's length whereas in Korea it has been carried out in a more direct, intimate manner paralleling that of a partnership.

Why such direct interaction may have worked well to promote export and economic growth in Korea when the conventional wisdom generally sees it as unworkable and counterproductive still remains very much a puzzle or an "apparent paradox" (Parvez Hasan 1976, p. 29). It is toward the end of finding a solution to the puzzle or paradox that we investigate the institutions of the government-business relationship and its cultural basis. 
III. Government-Business Relationship in Korea

Korea's manufacturing sector has a clear dualistic structure consisting of two groups of firms. The first consists of large private enterprises which have benefited from subsidized credit and have been the major exporters of manufactured goods. The second group consists of numerous small and mediumsized firms which did not receive preferential loans and had little direct contact with the government.

In 1982 , the 30 largest business groups accounted for 40.7 percent of shipment, 18.6 percent of employment, 33.2 percent of value added, and 37.2 percent of capital stock in the manufacturing sector (Lee and Lee 1985). ${ }^{4}$ The dichotomous structure of the manufacturing sector is not in itself unique to Korea as the same structure is also found in many other countries. What distinguishes the Korean case from others is that the relationship that the government has maintained with these two groups of firms differs. With small and medium-sized firms it has maintained an arm's-length relationship, influencing their decisions with parametric measures such as regulations and price incentives. With large enterprises the government has maintained a much closer relationship often being directly involved with their decision-making process.

In the "Anglo-American 'free enterprise' economies" the government attempts to influence the decisions of business in two ways. First, it regulates business activities by stipulating the parameters within which they can be legitimately carried out. Second, it imposes taxes and provides subsidies changing the structure of price incentives and thus indirectly influencing the direction and magnitude of business activities. Regulations either prohibit certain actions or require compliance to certain conditions, and taxes and subsidies affect the calculus of profit from alternative 
activities and thus allow the government to select indirectly the activities that will be undertaken by business. With regulations and tax-subsidy the government maintains an arm's-length relationship with business and controls the environment in which business activities take place.

In Korea both regulations and tax-subsidies have been used to achieve government objectives, but there has been a much more direct contact between the government and large private enterprises. The interaction between the two was reinforced with the government control of the banking system, which was the most powerful among the instruments that the government possessed to achieve its objectives (Hong and Park 1986). Others included, for example, the Monthly Export Promotion Meeting which was initiated in 1965 and served as a forum for business and government. The meeting was chaired by President Park and attended by trade-related ministers, business association leaders, heads of major financial institutions, and representatives of major export firms. Institutional arrangements, legal and procedural issues, and other policy matters for promoting exports were discussed and fairly concrete policy recommendations and decisions were made on the spot. This forum contributed greatly to the elimination of innumerable bottlenecks that had impeded export growth.

IV. Cultural Foundation of the Government-Business Relationship Two questions arise with respect to the government-business relationship in Korea as an institution. Why was it established? And was it efficient? In answering the first question one might argue that the institution was simply a creation of an authoritarian government. This cannot be the answer, however, as there are countries with an authoritarian government which do not have a government-business relationship similar to that found in Korea. A new 
institution may be invented or imported from abroad, but for it to be successfully established and functioning in a society it must be accepted by the people of that society. This would be the case if the institution is congruent with the culture of the society. If this argument of cultural influence on the development of institution is correct, it also implies that the efficiency of an institution is not independent of the culture of the society in which it operates.

In his analysis of the successful development experiences of the countries of the Sinic culture Herman Kahn (1979, pp. 121-2) writes:

In the Confucian hierarchical society, the emphasis in on cooperation among complementary elements, much as in the family (which is in fact the usual paradigm or model in a Confucian culture). The husband and wife work together and cooperate in raising the children; each has different assigned duties and responsibilities, as do the older and younger siblings and the grandparents. There is emphasis on fairness and equity, but it is fairness and equity in the institutional context, not for the individual as an individual. Synergism--complementarity and cooperation among parts of a whole--are emphasized, not equality and interchangeability. The major identification is with one's role in the organization or other institutional structure, whether it be the family, the business firm, or a bureau in the government.

He then goes on to say (p. 122):

As opposed to the earlier Protestant ethic, the modern Confucian ethic is superbly designed to create and foster loyalty, dedication, responsibility, and commitment and to intensify identification with the organization and one's role in the organization. All this makes the economy and society operate much more smoothly than one whose principles of identification and association tend to lead to egalitarianism, to disunity, to confrontation, and to excessive compensation or repression.

The above quotes provide reasons for the existing institution and its efficiency. A Confucian society is a hierarchical society which values complementarity and cooperation among its constituent parts. ${ }^{5}$ Given this cultural foundation in Korea it could not have been difficult for the government to establish the type of relationship described above. The interaction between the private and public systems that Johnson has observed 
in Korea is not an interaction between two equal parts but between two cooperating parts in a hierarchical relationship. If the interaction has successfully led to the achievement of developmental objectives, it is in no small measure due to the cultural acceptance of the hierarchical relationship between government and business.

V. Culture and the Implementation of Government Policy

Although Kahn's characterization of a Confucian economy seems indisputable, he does not provide reasons why such an economy would operate more smoothly than the American and Western European economies. After all, the modern neoclassical economics in its most abstract form is the intellectualization of the efficiency of a market system composed of utilitymaximizing individuals and profit-maximizing firms. Such an economy has no hierarchical relationship and no need for loyalty, dedication, responsibility, and commitment--the characteristics that Kahn attributes to the modern Confucian ethic, as the pursuit for self-interest suffices to bring about efficiency in the economy.

Even in such an economy there are two areas where culture could have an effect. The first is a firm or an internal organization which is a hierarchical organization. Here, opportunism and lack of information could affect the efficiency of the organization, and to the extent that culture constrains opportunistic behavior and improves communication among the members of the organization it would enhance efficiency. Clearly, it would appear that the Confucian ethic that fosters loyalty, dedication, responsibility, and commitment and intensifies identification with the organization and one's role in the organization would limit opportunistic behavior more than the Western egalitarianism. Cultural influence on the operation of an internal 
organization is a topic of great interest as recently Japanese firms are seen as being more efficient than American firms and reasons are sought for the difference. This is, however, a subject matter that we leave to others.

The second area where culture could affect is the relationship between government and business. In the paradigm of neoclassical economics the role of government is to intervene with decisions of private business only when there are market failures. and then to intervene with functional incentives such as taxes and subsidies and to bring about income redistribution with nondistortionary lump-sum tax if equitable distribution of income is a societal objective. Although this paradigm is presented as being culture-neutral, it cannot be as it ignores the question of the effectiveness of functional incentives, tax avoidance and evasion, and rent-seeking activities which could be influenced by cultural norms. If taxes can be avoided and subsidies can be taken without complying to their conditions, they they cannot be effective in directing resource allocation. Moreover, with rent-seeking activities actual taxes and subsidies established through legislative processes may not be those that would direct resources toward growth objectives. In other words, even if policies are designed to achieve economic efficiency and promote economic growth, they may not be effectively implemented as regulations and taxes are avoided and subsidies fail to modify recipients' behavior. Policies can be, of course, more effectively implemented if more resources are devoted to their implementation. But then at some point the cost of implementation could exceed the benefit from the policies. It clearly follows that if certain cultural characteristics help reduce the implementation cost a society with such culture will be better off than a society without it.

As noted above, in Korea a partnership has existed between government and business wherein the government undertook the role of a senior partner and 
business that of a junior partner. There was direct contact between the government and business through channels such as "deliberation councils" and "discussion groups," which facilitated the exchange of information more direct than possible through markets. To better understand how policies were formulated and implemented in this framework of the relationship it is useful to regard the government and large enterprises in Korea as an internal organization. Unlike, however, most private internal organizations the relationship within this internal organization is not entirely in the form of administrative processes as prices are also used to influence the decisions of the enterprises. Furthermore, the boundary of the organization is not legal and its constituent enterprises may change from time to time. For these reasons and to differentiate this internal organization from private internal organizations it is proposed that the hierarchical organization consisting of the government and large private enterprises be called the quasi-internal organization. When policies are implemented within this organization they are said to be implemented through the internal organizational mode whereas when they are implemented through markets with regulations or tax-subsidies they are said to be implemented through the market mode of policy implementation. Both modes of policy implementation are affected by the culture of the society. Which mode of policy implementation is then more economical for which culture? This is a difficult question to answer as the cost of policy implementation is affected by factors such as the size of the economy and the state of its development as well as culture. One could argue, however, in the case of Korea in the 1960 s and 1970s its Confucian culture favored the internal organizational mode; that is, it was a more efficient mode of implementing the policies of the developmental state than the market mode. The relatively small size of the economy and a relatively small number of 
large enterprises that the government oversaw meant that communication between the government and the enterprises could be easily carried within the quasiinternal organization. Direct contact was possible on a one-to-one basis, facilitating the flow of information from the enterprises to the government and the flow of directions from the government to the enterprises. With a large number of enterprises to oversee such contact would become more costly, and the arm's length relationship of the market mode of policy implementation would become more efficient.

In arguing, that economic transactions can be more efficiently carried out in an internal organization than across markets Williamson (1986) points out that hierarchy extends the bounds of rationality by improving the specialization of decision-making and economizing on communication expenses; reduces opportunistic behavior as it commands more incentives and control techniques than possible with independent agents; reduces uncertainty as independent units in an internal organization can coordinate whereas they could not if they were separate entities in markets. For these and other related reasons vertical integration can be more efficient than two independent firms linked together through market by reducing transaction cost between the two units.

When two independent firms become vertically integrated, a new hierarchy is established and no one in the new firm questions who has the authority to make what decisions. The order of the hierarchy is legal and based on property rights although there might be some cultural influence on it, and with the ready acceptance of the order the internal organization can benefit from its organizational structure.

The quasi-internal organization is different, however. For large private enterprises to accept the role of a junior partner and for the government to 
play the role of a senior partner both parties must accept their respective role as being a norm. In America and the West where the form of government is a representative one and is seen to represent the interests of constituent groups, large enterprises are not inclined to accept the government as a senior partner. In the countries with the Confucian ethic where five basic unequal relationships betwen ruler and subject, father and son, older brother and younger brother, husband and wife, and older friend and younger friend are accepted as a norm and where these relations are based on mutual, complementary obligations, the quasi-internal organization is not an institution that will be opposed or resisted. Given this ready acceptance the quasi-internal organization can realize the advantages of hierarchy.

VI. Conclusion

The culturally-conditioned acceptance of the quasi-internal organization in Korea does not mean that the force of the hierarchy was completely cultural. It was in part based on the authority of the government to tax and to grant subsidized credit. That is, the acceptance of the role of a junior partner on the part of large private enterprises was in part forced by necessity and in part cultural. With the recent political democratization the form and intensity of the relationship between government and business have changed somewhat. As the economy develops further and as political democratization proceeds, the relationship will inevitably change, improving the efficiency of the market mode of policy implementation over that of the internal organizational mode. The quasi-internal organization will then cease to exist, having served its useful function during the early stages of Korea's economic development. 


\section{Footnotes}

1. The way the economics profession, at least in North America, has treated the bodies of work that reach out beyond the confines of neoclassical economics is aptly described by Ruttan (1988, p. S255): "Professional opinion in economics has not dealt kindly with the reputation of those development economists who have made serious efforts to incorporate cultural variables into development theory or into the analysis of the development process. Their work has typically been favorably reviewed and then ignored. Their work has had wider currency outside than within the field of economic development. There has been no rush by other scholars or by graduate students to refine or test either their theories or their results."

2. Here, we define culture as "the collective programming of the mind which distinguishes the members of one category of people from another" (Hofstede and Bond 1987). Thus, cultural and institutional parameters include religion, educational system, legal system, labor institutions, family, etc. These parameters contribute to the milieu of a society in which various economic actors play their respective roles and in which economic development does or does not take place.

3. A counter argument against a cultural determinism of economic development can be, however, provided by citing the case of People's Republic of China and Vietnam which share the same cultural background with the more successful Asian economies but belong to a different ideological camp.

4. When Korea's industrial development began in 1961, small and medium-sized firms accounted for close to 80 percent of employment in mining and manufacturing and their share of output and value added was more than 65 
percent. The shares of employment, output and value added, however, decreased continually till 1973. Although they have increased gradually since then, they are not as dominant as they were in the early 1960s (Lee and Lee 1985).

5. It needs to be pointed out that there is some difference in Confucianism practiced in China, Korea, and Japan. According to Morishima (1982), the Japanese place loyalty above benevolence, filial piety, faith, and bravery whereas in China and Korea benevolence is of central importance. Whether this difference has any effect on the respective countries' economic development is a question yet to be answered. 


\section{References}

Arrow, Kenneth, "The Organization of Economic Activity," The Analysis and Evaluation of Public Expenditure: The PPB System, Joint Economic Committee, 91st Congress 1st Session, 1969, 59-73.

Balassa, Bela, The Process of Industrial Development and Alternative

Development Strategies, Princeton Essays in International Finance, No. 141, Princeton, N.J., Princeton University Press, 1980.

- The Newly Industrializing Countries in the World Economy, Pergamon

Press, New York, 1981.

Bauer, P.T., Dissent on Development, Harvard University Press, Cambridge, Mass., 1972.

Hagen, E.E., On the Theory of Social Change: How Economic Growth Begins, Dorsey Press, Homewood, II1., 1962.

Hofstede, Geert and Bond, Michael Harris, "Confucius and Economic Growth," mimeographed, Institute for Research on Intercultural Cooperation, University of Limburg at Maastricht, the Netherlands, June 1987.

Hong, Wontack and Park, Young Chul, "The Financing of Export-Oriented Growth in Korea," in A. Tan and B. Kapur (eds.), Pacific Growth and Economic Interdependence, Allen \& Unwin, Sydney, 1986.

Hoselitz, Bert F., "Non-economic Barriers to Economic Development," Economic Development and Cultural Change, 1952, 8-21. , Sociological Aspects of Economic Development, Free Press, New York, 1960.

Johnson, Chalmers, "Political Institutions and Economic Performance: The Government-Business Relationship in Japan, South Korea, and Taiwan," in R. Scalapino, S. Sato, and J. Wanandi (eds.), Asian Economic Development- 
-Present and Future, Institute of East Asian Studies, University of California, Berkeley, 1985.

Jones, Leroy P. and Sakong, Il, Government. Business, and Entrepreneurship in Economic Development: The Korean Case, Harvard University Press, Cambridge, 1980 .

Kahn, Herman, Wor1d Economic Development: 1979 and Beyond, Westview Press, Boulder, 1979 .

Kim, Duk-Choong, "Korea's Economic Strategy: Business, Government, and Economic Development," in M. Dutta (ed.), Research in Asian Economic Studies, Vol. 1, Part A, Asian Industrialization: Changing'Economic Structures, JAI Press Inc., Greenwich, Conn., 1988.

Lee, Chung H, and Naya, Seiji, "Trade in East Asian Development with Comprative Reference to Southeast Asian Experiences," Economic Development and Cultural Change, Vol. 36, No. 3, Supplement, April 1988, S123-152.

Lee, Kyoo Uk and Lee, Sung Soon, "Business Integration and the Concentration of Economic Power" (in Korean), Research Report 85-02, Korea Development Institute, Seoul, September 1985.

Lim, Youngil, Government Policy and Private Enterprise: Korean Experience in Industrialization, Korea Research Monograph No. 6, Institute of East Asian Studies, University of California, Berkeley, 1981.

Mardon, Russe11, "The Emergence of a Little Tiger: The State and Industrial Transformation in the Republic of Korea," a paper presented at the 1989 Annual Meeting of the Western Political Science Association meetings, Salt Lake City, Utah, March 30-April 2, 1989.

Morishima, Michio, Why Has Japan "Succeeded?", Oxford University Press, 1982. 
Myrda1, G., Asian Drama: An Inquiry into the Poverty of Nations, Pantheon, New York, 1968.

Scitovsky, Tibor, "Economic Development in Taiwan and South Korea: 1965-81," Food Research Institute Studies, Vol. XIX, No. 3, 1985, 215-264.

Ruttan, Vernon W., "Cultural Endowments and Economic Development: What Can We Learn from Anthropology?" Economic Development and Cultural Change, Vol. 36, No. 3, April 1988, Supplement.

Wade, Robert, "The Role of Government in Overcoming Market Failure: Taiwan, South Korea and Japan," to be published in Helen Hughes (ed.), Explaining the Success of East Asian Industrialization.

Weber, Max, The Protestant Ethic and the Spirit of Capitalism, Scribner, New York, 1958.

Whang, In-Joung, "The Role of Government in Economic Development: The Korean Experience," Asian Development Review, Vol. 5, No. 2, 1987.

Williamson, Oliver E., Economic Organization: Firms, Markets and Policy

Control, New York University Press, Washington Square, 1986. 